\title{
To Andreas Warnke, Professor of Child and Adolescent Psychiatry, Head of the Department of Child and Adolescent Psychiatry, Psychosomatics and Psychotherapy at the University of Wuerzburg, Germany, to celebrate his professional life and work at the occasion of his 65th anniversary
}

\author{
Claudia Mehler-Wex $\cdot$ Susanne Walitza $\cdot$ \\ Helmut Remschmidt • Manfred Gerlach
}

Published online: 5 December 2010

(c) Springer-Verlag 2010
This special issue is dedicated to a prodigious child and adolescent psychiatrist who has always truly cared for the well-being of his young patients regarding their situation from a holistic point of view. After his education in Montenegro, Brazil, and Frankfurt, Germany, Andreas Warnke not only studied human medicine but also psychology at the Universities of Gießen and Marburg and obtained his doctorate of human medicine in 1977. Primarily, he practised as a psychologist starting his child and adolescent psychiatry career at the Max-Planck-Institute at Munich in 1979, which he successfully continued at the University Clinic of Marburg (1983), where he became a Professor in 1989. Since 1991, he has been the head of the Department of Child and Adolescent Psychiatry at the University of Wuerzburg. Over the following decade, he was able to win over local social institutions and politicians and has extended and expanded his clinic by setting up a huge multi-professional out-patients' department, a beautiful day-clinic and an ultra-modern intense care unit. A highly specialized centre for mentally handicapped

\footnotetext{
C. Mehler-Wex ( $\square)$

University of Ulm, Department of Child and Adolescent

Psychiatry and Psychotherapy, Ulm, Germany

e-mail: claudia.mehler-wex@uniklinik-ulm.de

S. Walitza

University of Zürich, Department of Child and Adolescent

Psychiatry, Zürich, Switzerland

H. Remschmidt

Marburg, Germany

M. Gerlach

University of Würzburg, Department of Child and Adolescent Psychiatry, Psychosomatics and Psychotherapy, Würzburg, Germany
}

children and adolescents with psychiatric disorders will be opened during the next year. Despite his leading position and his numerous management tasks, he has never lost the kindness and warmth towards his patients and their families. Moreover, it has always been one of his most important issues to politically cement the relevance and esteem of child and adolescent psychiatry, psychosomatics and psychotherapy in professional and everyday life. Thus, he has been recognized and admired personally within managing boards of several leading committees such as the "Deutsche Gesellschaft für Kinder- und Jugendpsychiatrie" (DGKJP), the Committee of the German guidelines for Child and Adolescent Psychiatry, the European Association of Child and Adolescent Psychiatry (ESCAP) and the International Association for Child and Adolescent Psychiatry and Allied Professions (IACAPAP) to name only a few. Since 2008, Andreas Warnke has been the president of the association "World Federation of Attention Deficit/ Hyperactivity Disorder (ADHD)" founded in Zurich, Switzerland. Andreas Warnke has also been active on numerous journal editorial boards such as the "Zeitschrift für Kinder- und Jugendpsychiatrie und Psychotherapie", which is the most important child and adolescent psychiatric journal in Germany and for which he was the editorin-chief, the "Journal of Neural Transmission" and the recently founded journal "ADHD Attention Deficit and Hyperactivity Disorders". Finally, he has organized many successful congresses and initiated innovative congress categories such as in 1993 the "Arbeitskreis Biologische Kinder- und Jugendpsychiatrie", which was the first annual meeting for researchers of biological child and adolescent psychiatry in Germany, in 1996 the "Arzt-Lehrer-Tagung", an interdisciplinary meeting of school teachers and child and adolescent psychiatrists and in 1998 the "Würzburger Fachtagung Kinder- und Jugendpsychiatrie 
und Jugendhilfe" assembling child and adolescent psychiatrists and professionals of the youth welfare offices. In 2007, the 1st International Congress on ADHD organized by Andreas Warnke and one of us (M.G.) took place in Wuerzburg, Germany. A bridge between childhood and adult ADHD was built at the first time in this form. At the 2nd ADHD Congress in Vienna, Austria, outstanding scientists in the field of ADHD from all five continents, as well as participants from 70 countries witnessed the nomination of Andreas Warnke as the first president of the association "World Federation of Attention Deficit/ Hyperactivity Disorder". His great involvement and effort to bring together professionals who are looking after young people's well-being is one of Andreas Warnke's most outstanding merits.

This special issue is dedicated to a distinguished scientist. Quite soon in his professional career, Andreas Warnke set the foundations of his lifelong interest for both aetiological and biological, as well as psychosocial and therapeutic aspects of children and adolescents with deficits in writing and reading abilities. In collaboration with numerous national medical departments, he succeeded in collecting impressive samples of these patients, thus extending the empirical database in this field significantly and gaining international reputation and several awards such as the Hermann Emminghaus Preis in 1991. Apart from scientific papers and chapters, he has also published books on dyslexia for both academic and popular use supporting in this way the social acceptance and integration of young people afflicted with these problems. As the head of the Department of Child and Adolescent Psychiatry, Psychosomatics and Psychotherapy at the University of Wuerzburg, he moreover focused on neurobiological and neuropsychological aspects of psychiatric illnesses giving special attention to ADHD, anorexia nervosa and anxiety disorders. Predominantly, he has been interested in agedependent aspects of psychiatric illnesses and their course during the lifetime-his enthusiasm has resulted in many co-authorships and co-editorials of important educational books and manuals dealing with this subject. In order to complete the presentation of his main scientific interests, his work on the therapy of child and adolescent psychiatric disorders should be mentioned. $\mathrm{He}$ has initiated the national multi-centre competence network on therapeutic drug monitoring of the German Association of Child and Adolescent Psychiatry (www.tdm-kjp.de) with two of us (C.M.-W., M.G.) to improve the security of the patients and establish quality standards. His work has been primarily funded by the Deutsche Forschungsgemeinschaft (DFG) and the Federal Ministry of Education and Research (BMBF). Andreas Warnke is the Coordinator of the Klinische Forschergruppe KFO 125 "Attention-Deficit/
Hyperactivity Syndrome: Molecular Pathogenesis and Endophenotype in the Course of Treatment" funded by the DFG in 2005 and the research programme "Effects and Mechanisms of Psychotherapy in the Treatment of Attention Deficit Hyperactivity Disorder (ADHD) in Children and Adults". This national network is part of a research programme on psychotherapy in the treatment of psychiatric disorders founded by the BMBF in 2006. Andreas Warnke has authored over 300 scientific papers and chapters and edited 23 books - a body of work that has contributed much to our understanding of the aetiology of dyslexia and ADHD as well as treatment of child and adolescent psychiatric patients.

This special issue is dedicated to a gifted teacher. Andreas Warnke's illustrative and vivid talks presented with enthusiasm and brilliant rhetoric have always succeeded in filling the lecture rooms and delighting the auditorium. As for his students, he not only aimed at enriching their theoretical knowledge but also giving them the occasion to meet real patients in order to learn how to care for them adequately and treat them respectfully. He has mentored many young colleagues on their clinical and/ or scientific careers always sharing his wide-ranging knowledge. Not only once has he won the prize for the best lecturer of the University of Wuerzburg.

This special issue is dedicated to a particularly outstanding man, who has enriched people working alongside him with his warmth, cordiality, knowledge of human nature and holistic point of view. He has never been only interested in the professional performance and effectiveness of his colleagues, but he has always respected their personalities. With his humanity and sense of fairness, he has constructively enabled many individual careers. At his Department in Wuerzburg, he has been able to generate an atmosphere of great familiarity and friendliness between colleagues, staff members and collaborators. It is Andreas Warnke's distinguishing feature always to favour human personality and character instead of functional ambitions and sincerely care for his surroundings: "The most important issue of life is family, not professional success. Family always remains!"

We congratulate Andreas Warnke for a lifetime full of achievement, for his many valuable contributions to child and adolescent psychiatry and for enriching the lives of the students and colleagues who have been lucky enough to work alongside him. We also thank him for his friendship and warmth, which he has generously extended to the editors of this special issue, and to so many others throughout the past years.

All of us warmly wish you happiness and joy in the years ahead. 